\title{
Interpreting research in print
}

\section{A quarter-century update}

\author{
Franz Pöchhacker and Minhua Liu
}

It is not often that we as editors devote space in this journal to editorial matters and reach out directly to our readers. We assume that the readers of Interpreting are more interested in published content than in learning about the practices through which it comes about. Although the journal has certainly undergone an evolution over the years, the various changes have been relatively minor and have seldom merited explicit explanatory statements from the editors. Indeed, the journal's aspirations, practices and scope have remained largely unchanged since the first issue of the journal was put together a quarter of a century ago. It is therefore this anniversary - 25 years since Interpreting was first published, in 1996 - that we take as our prompt for the present update on some recent developments that, in themselves, might not need much explaining, and would probably go unnoticed by most authors and readers.

Before turning to what is new, or different, we take some pride in reaffirming what has remained unchanged. Aside from the journal's comprehensive scope, which encompasses all aspects of interpreting, approached from any disciplinary perspective (see Massaro \& Moser-Mercer 1996), the bedrock of Interpreting remains its aspiration to meet the highest standards of quality. First and foremost, quality here relates to the scientific work being reported, which, simply put, must be 'good research' in accordance with the field's theoretical and methodological state of the art; no less important, however, is the quality of the editorial process, from manuscript submission to publication in print.

\section{Editorial process}

Although they are set out in the journal's submission guidelines, the various steps in the editorial process are not always evident to authors, and remain practically invisible to readers. They are visualized here (Figure 1) to provide a point of reference for the update we give below. 


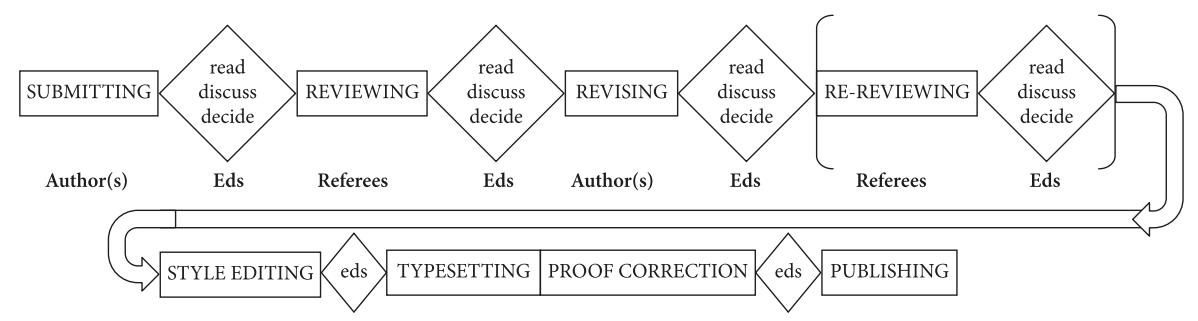

Figure 1. Editorial process

Like the journal's aspiration to quality, its editorial process has remained essentially unchanged. This also includes submission and communication via email rather than an online platform for manuscript management. Although online submission systems certainly have their advantages, we very much appreciate the direct personal communication we have with our authors and reviewers. At the same time, we value the affordances of social media, and we are happy to announce in this editorial that Interpreting has a Twitter account (@InterpretingJ), which will be used to reach out to our research community and readers and inform them about journal-related news.

The process that is initiated by the submission of a manuscript is depicted in Figure 1 as two phases, the first of which (upper sequence) is concerned with content and the second with form. As highlighted by the agent labels underneath the individual steps, the first and main editorial phase (i.e., the upper sequence) involves multiple collaboration among authors, editors and referees. What is less evident is the crucial role of the referees in the journal's (double-blind) peerreview procedure. The journal's extended editorial team, including six associate editors and three times as many advisory board members, offer much support at this stage, even though the volume and degree of specialization of submissions are such that at least as many referee reports have to be commissioned from other reviewers. It is precisely because of this constant thematic and methodological evolution of the field that the journal's editorial board, and particularly the advisory board, requires some renewal from time to time. The most recent changes in the team of editorial advisors are described in more detail below.

In the form-oriented part of the editorial process (Figure 1, lower sequence), style editing constitutes a vital part of quality assurance, and here too we are happy to introduce a new member of our team. Furthermore, a consequential technical innovation will be described for the final stage of the process, before we devote the remainder of this text to some concluding reflections on recent trends from our perspective as editors. 


\section{Editorial team}

\section{Associate editors}

Ever since the journal's relaunch in 2003, the team of six associate editors has remained highly stable. In 2012, when the journal lost its longtime devoted editor, Miriam Shlesinger, the renewal of the larger editorial team involved only a minimal change in that respect: Birgitta Englund Dimitrova and Cecilia Wadensjö, with the same institutional affiliation, merely exchanged places, the latter taking on the role of associate editor. In the present renewal, two long-serving associate editors stepped down after retiring from their academic positions: Roda Roberts, who was a driving force behind the emergence of community interpreting as a fast-growing field of practice and research in the 1990s and went on to become heavily involved in lexicography as the Director of the Bilingual Canadian Dictionary project; and Cynthia Roy, who was no less influential in the development of research and teaching in the area of signed language interpreting. We are profoundly grateful to these two leading scholars for supporting our journal with their unique expertise and international reputation over so many years.

The two new associate editors appointed in the course of 2020 are Bart Defrancq, of Ghent University, and Graham H. Turner, of Heriot-Watt University, Edinburgh. Both of these colleagues are well-known published authors and need little introduction. Among their other accomplishments, they have authored papers and reviews in Interpreting, and Graham Turner served on the journal's advisory board from 2013. We are happy that they have agreed to take on the more active role of associate editors who assist us with urgent or complex vetting and reviewing tasks and advise us when needed in matters concerning the journal's policy and management.

\section{Advisory board}

Aside from the change mentioned above, three more advisory board positions became vacant in 2020 as a result of our efforts to keep our team of expert advisors up to date. Kirsten Malmkjær, who (co-)edited Target from 2000 to 2013 and is an accomplished editor of several scholarly handbooks, ended her 17-year tenure on our advisory board, where she had ensured close links with such areas as English linguistics and translation theory. The two other outgoing advisory board members had been serving the journal in that capacity from the very beginning, that is, over a quarter of a century. Patrick Twidle, then with the European Parliament, represented a visible link to the European institutions on the advisory board. He continued in that role after moving to the European Union's Court of Justice until 
his retirement in 2016. An even more active founding member of the editorial team was Jennifer Mackintosh, whose distinguished career in the field of conference interpreting spans four decades. The President of AIIC, the International Association of Conference Interpreters, from 2003 to 2005 , she had been among the research-minded practitioners of the 1980 os who actively promoted the field's renewal and opening up that Daniel Gile (1994) has labeled the "Renaissance" of interpreting research. In that same spirit, Jennifer Mackintosh teamed up with the founding editors of Interpreting back in 1996 not only as a member of the advisory board, but also as the journal's first English Language Editor, as the position was then called. Her long-standing commitment to ensuring both close ties between academic research and the profession and high standards of quality in the way research is presented in writing deserves our heartfelt thanks and appreciation.

Although this would be a good place to introduce the original English Language Editor's most recent successor, we will first complete our description of the new advisory board by introducing its new members. We should preface this by stressing how difficult it is to achieve a degree of renewal and updating when the unique expertise of current members is to be retained while the list of advisory board members must not become excessively long. Faced with the ongoing diversification and specialization of our field, we have therefore requested and obtained permission from the publisher not only to fill the four vacancies but to appoint a total of six new advisory board members. As listed with their academic affiliation on the journal's website and in the print edition's front matter, these are, in alphabetical order: Chia-chien Chang, Chao Han, Brooke Macnamara, Christopher Mellinger, Brenda Nicodemus and Christopher Stone, all of whom have authored and/or reviewed papers in Interpreting. With three of these scholars based in the USA and two with a Chinese background, there appears to be a certain bipolarity, but this is rather coincidental as far as the preponderance of American affiliations is concerned. The presence of scholars from mainland China and Taiwan, on the other hand, reflects the evident growth and visibility of what some might call Chinese interpreting studies. Interpreting paid tribute to the increasing importance of "China and Chinese" in our field with a special issue on that theme back in 2009, and following a steady rise in the number of contributors with a Chinese background, the second issue of Volume 20 (2018) was the first to feature a majority of such authors. It is therefore high time for this trend to be reflected also in the composition of our advisory board, and we are happy that we are able to count on the support of Chia-chien Chang and Chao Han.

No less important a trend in interpreting studies has been the continuous advance of research on signed language interpreting, and we hope to do justice to it by appointing three new advisory board members with relevant expertise, ranging from cognitive approaches, including a strong experimental tradition, 
to broader professional and educational concerns and ethnographic methods: Brooke Macnamara, Brenda Nicodemus and Christopher Stone. While all these colleagues have been invited because of their credentials as researchers, it is also worth mentioning Christopher Stone's leadership position in the profession as President of the World Association of Sign Language Interpreters (WASLI). This is reminiscent of the way Jennifer Mackintosh straddled the interests of research and the profession earlier in this century, for a different domain of professional practice.

Last, but not least, Chris Mellinger reinforces our advisory team not only as a scholar with ample experience in authoring and editing, but especially through his rich expertise in matters of quantitative research and statistical analysis. The growing use of increasingly sophisticated statistics in research on interpreting is, in principle, certainly a welcome trend; at the same time, a thorough understanding of such techniques cannot normally be expected of interpreting scholars who come from distinctly profession-oriented training programs. The appropriate use of statistical techniques, though at a more advanced level, therefore remains as big a challenge in our field as it was 25 years ago when Interpreting was founded. It was no coincidence that all five associate editors recruited by Barbara MoserMercer and Dominic Massaro had a background in psychology - a field whose experimental tradition held the promise of the highest scientific standards in the eyes of the founding editors.

\section{Style editor}

That high scientific standards should be matched by high standards of editorial quality was mentioned earlier as a fundamental assumption for this journal. Living up to it in a community of scholars from increasingly diverse linguistic and cultural backgrounds would not be possible without the professional skills of a copy-editor, or style editor. But while such services are offered widely on a purely commercial basis, they are hardly affordable for a specialized academic journal, where compensation for editing work is offered, if at all, only at a fraction of commercial rates. It is only when skill comes with a sense of devotion to the field that excellent style editing becomes viable. This applied to Jennifer Mackintosh for the first five volumes of Interpreting; subsequently to associates of Miriam Shlesinger; and then, from 2007, to herself, until her untimely death in 2012. It also applied to Peter Mead, who, as an interpreting scholar himself, epitomized this profile and shared his thoughts about it in this journal (Pöchhacker \& Liu 2019). It naturally proved difficult to find a successor who would work at a comparable level of commitment. We therefore feel exceptionally fortunate that a highly devoted professional with experience in copy-editing texts in translation studies has agreed to be 
our Style Editor as of the present volume. John D. Linnegar has over 30 years of experience as a writer, copy-editor and proofreader, and has been training editors and proofreaders since 2000, aside from co-authoring books on the subject. His sense of mission is aptly expressed in his email signature, which characterizes him as "author's advocate and reader's ambassador".

\section{Online first}

Regarding the second (lower) sequence in the process depicted in Figure 1, there has been a significant change also at the end of the editorial process. Since 2020, Interpreting has been publishing citable content 'online first', meaning that articles, reports and book reviews for which the editorial process, including typesetting and proofreading, has been completed are made available on the publisher's e-platform (Interpreting - Online First). Within some four weeks after the editors submit the finished manuscript to the publisher for production, the publication is available to subscribers and to anyone else wishing to purchase access.

This new four-week production schedule is only a fraction of what it was when production was based on complete journal issues. This acceleration should not, however, obscure the fact that it is the first set of steps in the editorial process (i.e., the upper sequence in Figure 1) that accounts for the lion's share of the time that elapses from submission to publication. In an ideal case, 'time to publication' for an article can be as short as five or six months, whereas it is typically considerably longer. Aside from the weeks allotted to the initial screening ('vetting') of the submitted manuscript by the editors, it is the peer-review stage, followed by the author's revisions, that will often take many months. This part of the time to publication is expressed by the interval between the date of submission and the date of acceptance, which corresponds to the endpoints of the upper sequence of the process shown in Figure 1. In line with a new policy, these dates ('date received' and 'date accepted') will be indicated for all articles in Interpreting as of Volume 24. The date of online publication will then reflect the remainder of the process, that is, style editing and the four-week production process mentioned above.

The move to online-first publication greatly reduces the waiting time for authors to see their work in 'print' - at least online - before it is scheduled for inclusion in an issue. (Interpreting continues to publish two issues of approximately 160 pages each per volume.) At the same time, published content becomes available to readers and fellow researchers much more quickly, thus facilitating the timely uptake of new insights and findings. The uptake of published research by other scholars in and beyond the interpreting studies community in turn deter- 
mines the journal's standing in the landscape of academic publishing, and we will briefly say a few words here about our journal's impact factor and other metrics.

\section{Impact}

Among the various approaches to measuring and categorizing the 'value' of an academic journal, the best known is probably the so-called impact factor. Although it dates back to the 1960 s and came into widespread use in the latter part of the twentieth century, particularly in the sciences, it became an issue for translation studies journals only after the turn of the century (as did doubleblind peer-reviewing, for that matter). After persistent efforts by the publisher, Interpreting was included in the Arts \& Sciences Citation Index and the Social Sciences Citation Index and first given an impact factor in 2011, when the company managing the system was still Thomson Reuters (now Clarivate Analytics). By 2014, the impact factor, based on the number of citations to content published in the two preceding years, had risen from 0.250 to 0.579 , with a five-year impact factor of 1.059. (Unlike in fast-moving fields of scientific research, the metric based on the number of citations to content published in the five preceding years is widely regarded as more meaningful for the humanities and the social sciences.) The journal's two-year impact factor has since proved rather volatile. It declined to 0.333 for 2016 (with a more stable five-year factor of 0.923 ) and subsequently surged to 0.947 for 2018 , the highest impact factor among all translation studies journals in that year. By 2019, the five-year factor had climbed to 1.688 but it has since come down to 0.804 . These ups and downs remain largely inscrutable, but they do seem to be grounded in some relevant structural factors. After all, the journal has also seen a recent slip in the Scientific Journal Ranking relying on Elsevier's Scopus database, where it is classified in the categories of Language and Linguistics (Arts and Humanities) and Linguistics and Language (Social Sciences). After six years in the highest quartile (Q1), Interpreting was listed as Q2 in 2019 - a fate it incidentally shares with Meta. Nevertheless, Interpreting's CiteScore (a Scopus-based three-year impact measure) stands at 1.200, in between the CiteScores of 1.500 for Target and 0.800 for Translation and Interpreting Studies.

Other metrics reflect greater stability. The journal's Scopus-based $h$-index, for instance, which represents the number of $h$ items in the database that have been cited at least $h$ times, stands at 26, compared, for instance, to the $h$-index of 28 for Target (or 19 for Perspectives). As a comprehensive measure, the $h$-index is sensitive to both a journal's age (or date of inclusion in the database) and its scope. The latter, in particular, may hold some clues for assessing the compara- 
tive standing of Interpreting. Unlike general translation studies journals, such as Perspectives, Target, Translation and Interpreting Studies or The Translator, Interpreting has a relatively narrow scope and a correspondingly smaller community of researchers with this specialization. Combined with the ever-growing diversity of the field in terms of settings, modes, techniques and languages as well as theoretical and methodological approaches, the probability of a given publication being cited would tend to be much smaller than for a paper concerning translation more broadly. A case study on interpreting for deaf-blind persons might serve as an example compared to one on, say, literary translation or corpora in translation research. This also suggests that a competitive approach to journal rankings and citations would imply that editors include as one of their acceptance criteria a submission's broader appeal, and hence its higher probability of being cited. As editors of Interpreting, we would strictly oppose any such trend. Going down this route would favor mainstream topics and approaches and ultimately stifle the innovative dynamics that drive scientific progress in general and allow emerging practices, particularly in interpreting, to be explored.

Such considerations also have a direct bearing on the key criterion of quality. In the present context, 'good research' is not necessarily the same as 'most cited' By the same token, a journal's having a high impact factor is not necessarily a reflection of high-quality research. Rather, it is the editorial process which guarantees that each and every paper that is published meets the highest possible scientific standards. Which brings this discussion back to the sequence of decision-making illustrated in Figure 1.

Having set out the structure of the process in order to describe changes to some of its stages as well as to the team of human agents involved, we would like to devote the remainder of this text to a discussion of what we perceive as threats to the integrity and quality of published research on interpreting. These range from seemingly mundane issues such as workload all the way to cases of egregious academic misconduct.

\section{Quality under pressure}

\section{Volume and speed}

The growth of interpreting studies, which all of us certainly cherish as a positive development, is naturally reflected in an increasing number of publications. But this growth in output, fueled, of course, by the pervasive - and rising - pressure to 'publish or perish', has also been accompanied by a shift in publication types, mainly as a result of institutional policies that tend to value journal articles more 
than book chapters or even monographs. Since this is largely due to the belief in measurable impact (as discussed above), a belief held by both administrators and authors, an 'indexed' journal with a respectable impact factor, like Interpreting, will necessarily be a 'victim' of its own success, attracting a relatively larger share of the growing number of manuscripts. Thus, the number of submissions to Interpreting per year has increased sixfold in the course of the past 15 years.

Another trend linked to the growing volume of submissions is the ever-higher pressure being placed on early-career researchers to publish in scientific journals even before completing their $\mathrm{PhD}$, not to mention the option of pursuing an article-based $\mathrm{PhD}$. Unlike the publication pressure on confirmed academics, the injunction to 'publish early' increases the likelihood of submissions suffering from certain shortcomings due to their authors' lack of experience or insufficient supervisor support. Remedying these in one or two rounds of revisions with considerable editorial support places an extra burden on the entire process, partly shifting the workload from $\mathrm{PhD}$ supervisors or local mentors to journal editors and reviewers.

A problematic issue that is also associated with $\mathrm{PhD}$ projects, but not limited to them, is the 'slicing' of a single study into several papers, each usually submitted to a different journal. Where this is not done for reasons of space, the individual manuscripts are often not as strong and convincing as they could be, and authors risk rejection even though the research they are reporting on was substantial and sound.

Yet another adverse trend is what might be called 'journal shopping' - that is, submitting a manuscript that was rejected by one translation studies journal to another journal in the field, often with few, if any, revisions. Especially when the previous rejection was based on peer-review reports, this practice drives up the total volume of submissions to be processed.

Regardless of the underlying driving forces, the growth in the volume of submissions corresponds to a higher workload for those involved in the editorial process. This applies to editors and reviewers alike, and leads to a dual bottleneck: in the current editorial structure and process of Interpreting, there is a limit to the number of submissions the two editors can process (i.e., read and assess) as part of their overall academic workload; similarly, there is a limit to the number of manuscripts an editorial board member - or, indeed, any 'peer' with relevant expertise - can be asked to referee. Both of these limitations have an impact on the speed with which submissions to Interpreting can be processed.

On the fundamental assumption that the level of quality in the editorial process is to be maintained, the dual bottleneck means that the editors may experience a backlog of new submissions to be vetted, and the best-qualified referees for a given manuscript may need to be given more time to do yet another 
review in their field of expertise. The peer-review bottleneck might conceivably be resolved by a wider distribution of the workload, but this option is limited by the composition of interpreting studies as a field of research. Although detailed socio-bibliometric data are lacking, it is fair to say that interpreting studies as a relatively young (sub)discipline is structured as a flat pyramid, much like the population pyramid of a 'developing country': a broad base of one-time authors and early-career researchers lies beneath a much narrower middle tier of researchers holding academic positions, and there is a narrow peak of highly experienced scholars. In more firmly institutionalized fields, the pyramid might look more like a tower. Significantly, this structural discrepancy between early-career scholars and more senior members of the research community applies both to the field as a whole and to specific topics and methodological specializations (such as assessment, court interpreting, ethics, multimodality or remote interpreting, to name only a few). This makes it difficult for editors to recruit the best-qualified peers for each reviewing task: scholars with relevant expertise and experience - and the readiness to serve fellow authors, editors and the field in that capacity - are simply in short supply. On the other hand, casting the net more widely, beyond the set of 'true peers' for a given study, poses the risk of receiving less informed reviewer feedback, which potentially reduces the chance of attaining the best possible published outcome.

Beyond these considerations for the mainstream discipline, the peer-review bottleneck also applies to the field's manifold interdisciplinary dimensions. Commissioning review reports from specialists in such fields as cognitive psychology, public health or forensic linguistics (for papers on, say, working memory, the clinical impact of interpreter use or interpreted testimony in jury trials, respectively) is an excellent strategy for tapping into relevant expertise, but it is one that often clashes with such specialists' workload, not least as reviewers, in their own field.

The solution that has been adopted by Interpreting (and comparable journals) to ease the peer-review bottleneck is based on stricter assessment at the editorial vetting stage, which corresponds to a rising percentage of so-called desk rejections. This ratio has become inverted over the years, from only 10 to 20 percent of submissions that were rejected without being moved to the peer-review stage to a current desk rejection rate of 70 to 80 percent. While this eases the pressure on peer reviewing, it obviously exacerbates the pressure on the editors, who need to give an informed assessment of the manuscript in explaining why it cannot be accepted for publication. (That early-career scholars often express their appreciation for such feedback, valuing it as a learning experience, is gratifying for the editors, but it tends to do the opposite of easing their workload.)

Thus, as illustrated in Figure 2, safeguarding quality as the guiding principle throughout the editorial process is crucially conditioned by not only the volume 
of submissions but also the speed with which authors can and should expect their submissions to be processed. In the triangular relationship, it seems more feasible to satisfy the demands of any two of the three components (i.e., volume + quality - speed; volume + speed - quality; quality + speed - volume) than to achieve a good overall balance. With reference to workload as a key determinant of the best possible outcome, the present discussion (and the visual summary in Figure 2) should also help explain why the issue of volume (i.e., more submissions) cannot easily be resolved by increasing the journal's 'volume size' (i.e., page count). The volume size of Interpreting has expanded since 2004 (Vol. 6) from 240 pages to 320 pages, but is likely to remain stable in the foreseeable future. Further expansion could come about only through a qualitative shift in the nature of submissions, that is, with more high-quality submissions that referees find acceptable with only minor revisions.

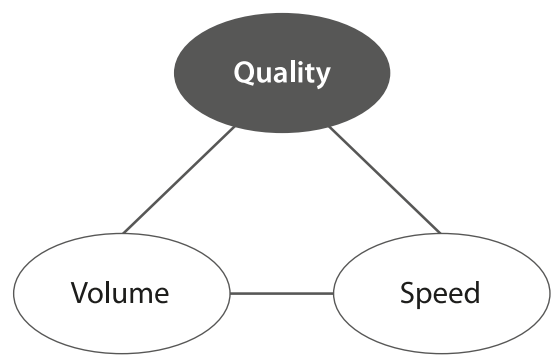

Figure 2. Quality in relation to volume and speed

Lest this account of our experience as 'editors under pressure' sound all too bleak, we are happy to conclude this section on a brighter note, before turning to yet more - and more serious - problems. The happy note was sounded by the author of a recently published article that largely met the optimistic scenario mentioned above: both reviewers had recommended only minor revisions, and even though the total time to publication was ten months, the author wrote: "You are the best (and fastest!) editors in the world." And a follow-up message read:

I remain profoundly grateful to you for the fantastic work you do for the journal and our discipline, and for being such attentive and responsive editors. It is truly a pleasure to work with you.

As explained above, much of this credit must go to our reviewers, who receive very little recognition for their devoted efforts and whose role in improving what is published is often noted only in a standard acknowledgement, if at all. It cannot be said often enough that the work of reviewers, in dialogue with the editors as much as with the authors, is absolutely vital to ensuring that what is published in 
Interpreting is of the highest possible quality, including, at times, the even more demanding effort of ensuring that some papers are not published there.

\title{
Plagiarists and predators
}

In a bibliometric analysis of journals in interpreting studies, Yan, Pan, $\mathrm{Wu}$ and Wang (2013:449) note that referees are expected to assess the quality of manuscripts, "in addition to a plagiarism check". Whether one agrees with this expectation or not, the topic of plagiarism in relation to academic journal articles had seemed quite alien to us - until an egregious case of plagiarism was brought to our attention in January 2018. A paper entitled "Evaluating emotional stability as a predictor of interpreter competence and aptitude for interpreting", which had been published in Issue 13:1 of Interpreting (Bontempo \& Napier 2011), was brazenly republished by IGI Global as a chapter in a 2015 Handbook of Research on Teaching Methods in Language Translation and Interpretation edited by Ying Cui and Wei Zhao of Shandong University, China. Figures 3a and 3b show how this was done by contrasting the original abstract (Figure 3a) with the plagiarized one, by Fengxia Jiang of Beijing Foreign Studies University (Figure $3 \mathrm{~b}$ ):

\footnotetext{
This paper proposes that variance in interpreter performance is dependent on factors of both general cognitive ability and personality. Whilst there is no doubt of the interplay between individual personality traits and job performance across many occupations, the greatest interest lies in determining which traits play the most important role; and to what extent these variables impact on learning and achievement. The paper reports on a study of 110 accredited signed language interpreters in Australia. Psychological constructs of self-efficacy, goal orientation and negative affectivity were measured, as were interpreter ratings of self-perceived competence as practitioners. The most significant finding revealed the dimension of emotional stability (represented on the negative end of the continuum by traits of anxiety and neuroticism, and measured in this study by the negative affectivity scale) as a predictor of interpreter's selfperceived competence. Based on these findings, recommendations for admission testing and interpreter education curricula are discussed.

(๑) 2011 John Benjamins Publishing Company
}

Figure 3a. Original abstract (Bontempo \& Napier 2011: 85)

\begin{abstract}
Chapter 19
Evaluating Emotional Stability as a Predictor of Chinese MTI Students' Interpreter Aptitude .......... 362 Jiang Fengxia, Beijing Foreign Studies University, China

Chapter 19 proposes that variance in interpreter performance is dependent on factors of both general cognitive ability and personality. It reports a study of 110 MTI students in China in the hope of finding out what traits play the most important role and to what extent these variables impact learning and achievement. Psychological constructs of self-efficacy, goal orientation, and negative affectivity were measured. The most significant finding revealed the dimension of emotional stability as a predictor of interpreters' self-perceived competence. Based on these findings, recommendations for admission testing and interpreter education curricula are discussed.
\end{abstract}

Figure $\mathbf{3}$ b. Plagiarized abstract by Fengxia Jiang

We wrote to the publisher in early 2018 , supplying all the evidence and demanding the retraction of the plagiarized material as well as the publication of a retraction notice, as stipulated in the publisher's policy document on ethics and malpractice: 
"Work which has been found to contain plagiarism will be removed from all IGI Global electronic database products. A statement of notification and retraction will be included at the electronic database link providing the citation for the original work" (IGI Global 2021). The publisher's compliance was highly superficial, however. The chapter was deleted from the Handbook's table of contents, but despite repeated follow-up complaints, it remains in the publisher's electronic database as well as printed publications (such as the copy of the Handbook held in the library of the University of Vienna) to this day. (The excerpt shown in Figure $3 \mathrm{~b}$ was accessed on the publisher's website in January 2021.) This also applies to the version republished in 2016 in a three-volume collection of assorted IGI material under the title Psychology and Mental Health: Concepts, Methodologies, Tools, and Applications, 'edited' by Information Resources Management Association. Nor did Jean-Christophe Penet (2015), of Newcastle University, who wrote a highly favorable review of the Handbook that was published in The Journal of Specialised Translation (JoSTrans) in 2015, notice anything untoward about Chapter 19 by Fengxia Jiang.

IGI Global's (2021) policy document on ethics and malpractice also states that "Authors of work containing plagiarism will be prohibited from publishing with IGI Global for an allotted period or indefinitely, at the publisher's discretion." Nevertheless, the plagiarist, Fengxia Jiang, served as founding editor of IGI Global's International Journal of Translation, Interpretation and Applied Linguistics (IJTIAL), with an editorial board of associate editors made up exclusively of academics affiliated to Beijing Foreign Studies University (BFSU), especially the Graduate School of Translation and Interpretation (GSTI).

Despite our written complaints to the dean of the School as well as to the University's leadership, Fengxia Jiang continued in her position as Associate Professor in BFSU's GSTI until 2020, when she was allegedly transferred to a different faculty. It was at least much sooner that she was replaced as editor of IJTIAL by the two handbook editors who had published her plagiarized paper, Ying Cui and Wei Zhao of Shandong University. The latest change in the journal's only twoyear history is particularly significant: not only was Wei Zhao joined by a coeditor from Beijing Foreign Studies University (Lin Fan, who obtained her PhD from Shandong University), but the journal, still managed under the publisher's name, is now 'open access', funded by Shandong University. IJTIAL claims to operate a double-blind peer-review policy, relying on members of its 16-member Editorial Review Board - in which expertise in interpreting is hard to make out. Although it is beyond the scope of this editorial to attempt a qualitative assessment, the first paper published in Issue 3:1 (2021), co-authored by two academics from universities in mainland China, can safely be classified as 'junk science'. It is entitled "A Better Medical Interpreting Service: Interpreter's Roles and Strategies 
Under Goffman's Participation Framework", and a member of the editorial board of Interpreting who kindly read the paper for a summary assessment characterized it as "more like some kind of dodgy propaganda than a piece of research."

Most strikingly, the IJTIAL editors' (and publisher's) readiness to accept and market sub-par research was in evidence as an explicit strategy when they wrote to journal editors in translation and interpreting studies to ask them for rejected manuscripts. Faced with a shortage of manuscripts for their inaugural issue, Wei Zhao and Ying Cui wrote: "We know this may sound a little abrupt but could you kindly direct the authors of the rejected submissions to the submission link of IJTIAL" (email to Loredana Polezzi, 15 September 2018).

While unacceptably poor standards of scholarship and editorial quality must be of most serious concern to our research community, the practices of this publisher are no less problematic regarding the business dimension of publishing. Papers in the journal's inaugural volume, including any rejected manuscripts the editors may have rounded up, still sell for 37.50 US dollars a piece. Similarly, Volume 2 (2020) of IJTIAL consists of nine papers, with a total of 120 pages; IGI Global sells the print copy at a list price of 860 US dollars, which is three times the price of a volume of Interpreting, which has twice the number of pages.

Without going into further detail, there can be little doubt that what we are up against here is not only poor editing and scholarship but also predatory publishing. This issue has been widely discussed in the broader scientific community for quite some time, but there seems to have been little awareness of or concern about it among translation and interpreting scholars. As illustrated by the case of IGI Global and IJTIAL, predatory publishing practices and open access publishing can intersect in different ways. Well-intended open access publishing policies, such as the recent Plan S initiative promoted by an international consortium of research funding organizations, may cause undesirable side-effects, when funding and profit sources are shifted without due regard for quality-assurance measures. The efforts of Jeffrey Beall (e.g. Beall 2016), who saw open access publishing as fueling predatory publishers and compiled and publicized a list of predatory journals from 2008 until 2017, have done much to raise awareness in the scientific community at large. Nevertheless, the unique nature of different fields of research makes it imperative to consider the issue in the specific context of a given discipline, such as translation and interpreting studies, in order to assess the extent to which it may pose a threat.

Once again, a broader discussion of predatory publishing and junk science in translation studies is beyond the scope of this editorial paper, but a clear warning message must nevertheless be sounded. Most academics today have been exposed, if not become used to, spam messages from 'editors' of predatory journals soliciting submissions, and these are often presented and worded so poorly 
that they are easily disregarded. But the grey zone between junk and high-quality journals is expanding, and translation and interpreting scholars, particularly in the early stage of their careers, will have to be better informed and more alert in order to contain the spread of dubious publishing practices in our field.

Given the focus of this text, we end this section by stressing the special responsibility that journal editors and reviewers have for counteracting the threat posed to the integrity of research in our field by academic and commercial malpractice. By way of example, we mention a recent submission to Interpreting (received 15 March 2020) by three academics from universities in mainland China. The manuscript, on "eye tracking in Chinese-English sight translation", was poorly written but reported substantial analyses of a solid corpus of empirical data. Following a preliminary inquiry with the authors about a vaguely cited source, we decided to send the manuscript to an expert peer. It was this conscientious peer reviewer who alerted us to the fact that the authors had lifted the entire analysis from an unpublished (uncited) Master's thesis defended in Taiwan. Confronted with the evidence, the first author, a professor of Nankai University, claimed to have no knowledge of the matter and put the blame (rightly, we believe) on the second author, a rogue visiting scholar to Nankai University in collusion with the third author. Needless to say, a bit less attention in the editorial screening, a more casual choice of referee and a somewhat shallower peer review would have eased the way of this plagiarized manuscript into an issue of Interpreting in the year of its 25 th anniversary.

\section{Integrity and transparency}

The phenomena and forces described in the previous sections pose a threat to the quality and integrity of published research on interpreting. As we have tried to show, problems range from higher numbers of low-quality submissions to a shortage of highly qualified and committed expert referees and to outright violations of scholarly integrity. At least as far as Interpreting is concerned, we can be confident that our current structure, editorial procedures and - not least - an extended editorial team are as strong as they could be, and will serve to safeguard the highest possible standards of published research on interpreting in the years ahead. But our journal is not alone, and scientific research is not only an individual achievement but also an inherently collective endeavor. More than ever, we depend for our work on the efforts of others in our scientific community, and this includes other journals and editors working to comparable standards.

As our examples have shown, pernicious practices are steadily making inroads into our field and seem to be gaining ground and respectability. Books by publishers of questionable repute and substandard editorial practices are being 
reviewed (and praised) in respectable journals, and widely known and cited authors publish papers and edit volumes with dubious publishers. A recent example is a co-edited special issue of IGI Global's IJTIAL - noteworthy for the fact that the call for papers for this publication has been widely circulated in the translation studies community, including via the periodic "email digest" of EST, the European Society for Translation Studies, and the equally appreciated Translation News bulletin published by Jorge Díaz-Cintas.

These developments are likely to fuel the problem of 'citation contamination', that is, the inclusion of references to papers in predatory journals. A manuscript submission to Interpreting by academics from Iran, for instance, came with a bibliography that looked almost like an excerpt from Beall's List. While such cases can be dispensed with by a desk rejection, 'contaminated' references can also be found in otherwise acceptable manuscripts, and it is unclear to what extent reviewers could be expected to be alert not only to plagiarism but also to dubious references.

What our entire community should definitely be alert to, beyond the variety of poor scholarly practices, is threats to the institutional integrity of academic publishing. We are referring here to the case of a university in mainland China financing the publication of an international journal published under the name of an international publisher. The example given above was Shandong University now funding IGI Global's open access IJTIAL. Against this backdrop, the launching of Interpreting and Society, a new international journal published by SAGE but funded by Beijing University of Foreign Studies, deserves particular attention. With its more specific orientation, the new journal is certainly a very welcome addition to the range of outlets for research on interpreting. Its two editors, Julie Boéri (Hamad Bin Khalifa University) and Wen Ren (Beijing Foreign Studies University), and their editorial board composed of well-established international scholars, can be expected to aim for high standards of quality. Given the institutional, political and sociocultural network in which this venture is embedded, however, they may well be facing a difficult challenge. Further collaboration in and beyond our research community, of the kind that has helped Interpreting steer a promising course over the past quarter-century, should serve to meet that challenge - in the interests of our shared goal of safeguarding and promoting the integrity of interpreting studies and the quality of published research on interpreting in the years to come. 


\section{References}

Beall, Jeffrey (2016). Best practices for scholarly authors in the age of predatory journals. Annals of the Royal College of Surgeons of England 98, 77-79. https://doi.org/10.1308/rcsann.2016.0056

Bontempo, Karen \& Napier, Jemina (2011). Evaluating emotional stability as a predictor of interpreter competence and aptitude for interpreting. Interpreting 13 (1), 85-105. https://doi.org/10.1075/intp.13.1.06bon

Gile, Daniel (1994). Opening up in interpretation studies. In M. Snell-Hornby, F. Pöchhacker \& K. Kaindl (Eds.), Translation studies - an interdiscipline. Amsterdam: John Benjamins, 149-158. https://doi.org/10.1075/btl.2.2ogil

IGI Global (2021). Ethics and malpractice. https://www.igi-global.com/about/rightspermissions/ethics-malpractice/ (accessed 8 January 2021).

Massaro, Dominic \& Moser-Mercer, Barbara (1996). Editorial. Interpreting 1 (1), 1-6. https://doi.org/10.1075/intp.1.1.01mas

Penet, Jean-Christophe (2015). Review of Y. Cui \& W. Zhao (Eds.), Handbook of Research on Teaching Methods in Language Translation and Interpretation (IGI Global, 2015). JoSTrans: The Journal of Specialised Translation 24, 262-264.

Pöchhacker, Franz \& Liu, Minhua (2019). Going out in style: An interview with Interpreting Style Editor Peter Mead. Interpreting 21 (1), 1-11. https://doi.org/10.1075/intp.00017.poc

Yan, Jackie X., Pan, Jun, Wu, Hui \& Wang, Ying (2013). Mapping interpreting studies: The state of the field based on a database of nine major translation and interpreting journals (2000-2010). Perspectives 21 (3), 446-473. https://doi.org/10.1080/0907676X.2012.746379 